\section{O lugar dos trabalhadores de saúde nas pesquisas sobre processos migratórios internacionais e saúde}

\author{
Health workers' place in studies on international \\ migratory processes and health
}

\author{
El lugar de los trabajadores de salud en las \\ investigaciones sobre procesos migratorios \\ internacionales y salud
}

\begin{abstract}
Resumo
Estudos sobre o processo saúde-doença-cuidados de imigrantes estabelecidos na cidade de São Paulo, Brasil, têm evidenciado uma complexa trama de relações nas demandas dos imigrantes e nas ações concebidas e planejadas pelos serviços de saúde. Nesse contexto, a intermediação dos trabalhadores da saúde na relação imigrantes-investigadores constitui importante forma de acesso dos últimos aos imigrantes sul-americanos, especialmente os bolivianos. Durante as investigações o acesso aos imigrantes ocorre dentro dos contextos das ações em saúde, facilitando aos pesquisadores o acesso às residências dos imigrantes, seus locais de trabalho ou mesmo organizações associativas. A compreensão dos processos de adoecimento dos imigrantes, dentro da complexa trama de relações entre trabalhadores institucionalizados em espaços organizacionais configurados por modelos de pensamento fundados na biomedicina, conduz-nos a problematizar sobre as possibilidades de aproximação junto aos sujeitos que compõem tal universo.
\end{abstract}

Imigrantes; Pessoal de Saúde; Pesquisa Qualitativa
Cássio Silveira 1,2

Alejandro Goldberg 3

Tatiane Barbosa da Silva 4

Mara Helena de Andrea Gomes 2

Denise Martin 4

\author{
1 Faculdade de Ciências \\ Médicas da Santa Casa de \\ São Paulo, São Paulo, Brasil. \\ 2 Universidade Federal de São \\ Paulo, São Paulo, Brasil. \\ ${ }^{3}$ Universidad de Buenos \\ Aires, Buenos Aires, \\ Argentina. \\ 4 Universidade Católica de \\ Santos, Santos, Brasil.

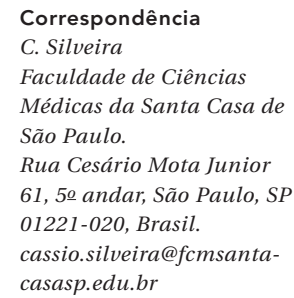


“A gente empresta os nossos olhos sobre a população para vocês"

(Agente Comunitária de Saúde, cidade de São Paulo)

\section{Introdução}

A assertiva proferida por uma Agente Comunitária de Saúde (ACS), trabalhadora da rede de atenção primária na área central da cidade de São Paulo, Brasil, transcrita em forma de epígrafe, delineia, em boa parte, os contornos das complexas relações existentes entre os trabalhadores da área da saúde e pesquisadores que têm se debruçado sobre a problemática dos processos de inclusão social de imigrantes pela política social em saúde.

Tomada em seu sentido mais imediato, essa afirmação pode provocar no leitor a ideia de que quem empresta quer de volta algo que, por suposto, lhe pertence. Indo além do imediatismo dessa interpretação, pode-se supor que o empréstimo tenha sido oferecido pela consideração ensejada em demonstrar a abertura que está sendo oferecida ao pesquisador de adentar ao conjunto de relações já existentes entre os imigrantes e os trabalhadores dos serviços de saúde. Ou seja, aquele que empresta só o faz porque o objeto de empréstimo, de alguma maneira, lhe pertence como algo que pode ser ofertado. Como uma ação de transportar o pesquisador para dentro de um universo que ele comumente examina à distância, os trabalhadores em saúde acabam por constituir-se como sujeitos de pesquisa que promovem importantes mediações com os imigrantes dentro dos processos de investigação.

Cabe-nos indagar "quem fala por quem?" na complexa trama de relações permeadas por ações derivadas de demandas dos imigrantes e de ações concebidas e planejadas pelos serviços de saúde. A intermediação dos serviços de saúde na relação sujeitos de pesquisa-investigadores acaba por se tornar o ponto de partida para projetos de pesquisa. A saber, a "porta de entrada" que dá acesso aos imigrantes em nossos processos de pesquisa, em mediações que conduzem as lideranças comunitárias, as lideranças domésticas, as lideranças laborais de oficinas de confecção e os agentes comunitários de saúde que visitam sistematicamente os imigrantes bolivianos.

Este artigo busca problematizar sobre as possibilidades de aproximação junto a imigrantes bolivianos no contexto dos cuidados em saúde no Município de São Paulo. Procurou-se provocar uma reflexão metodológica sobre a interação entre trabalhadores da saúde, pesquisadores e imigrantes bolivianos, com base nas inquieta- ções surgidas durante a realização do campo de pesquisa para coleta de informações de um estudo etnográfico sobre a tuberculose entre imigrantes bolivianos na área central da cidade de São Paulo.

As pesquisas sobre os processos migratórios e saúde, dentro do campo da saúde pública e, sobretudo, aquelas com o foco nos imigrantes bolivianos nas cidades de São Paulo e Buenos Aires (Argentina), mostram a complexa situação de saúde desse grupo de imigrantes. Por exemplo, a constatação de perfis etnoepidemiológicos específicos a cada grupo; o incremento de iniquidades associadas às desigualdades e modos de vida e de trabalho precários, a emergência das doenças infecciosas, como a tuberculose; a transposição, pelas fronteiras, de doenças endêmicas, como a doença de Chagas; além da constatação da existência de barreiras no acesso aos cuidados de saúde. As investigações têm evidenciado, também, que os imigrantes muitas vezes ressignificam ou mudam suas concepções e práticas sobre o processo saúde-doença-cuidados quando têm oportunidades de inserções nos serviços, mas com o agravante de que utilizam, com menor frequência, os serviços públicos de saúde quando comparados aos "nativos" $1,2,3,4,5,6,7,8,9,10,11,12,13$.

As trajetórias migratórias vivenciadas por bolivianos e bolivianas incluem, além dos deslocamentos fronteiriços pela América do Sul (Argentina, Chile, Paraguai e Brasil, particularmente), deslocamentos para a América do Norte (México, Estados Unidos e Canadá) e o continente europeu, com destaque para a Espanha. No Brasil, estudos sobre os deslocamentos migratórios e suas motivações $14,15,16$, sobre os movimentos transnacionais de trabalhadores da indústria de confecção ${ }^{17}$, sobre demografia 18 e sobre condições de vida e de saúde 9,10,19,20,21, já permitem compor um quadro analítico abrangente sobre a complexidade da situação migratória e das condições de saúde da população boliviana no país.

Com relação às abordagens teóricas sobre os processos migratórios, Wimmer \& Schiller 22 alertam para a forma como os estudos sobre migração em Ciências Sociais incorreram em reducionismos ao utilizar o nacionalismo metodólogico como forma de orientar as suas pesquisas. Esse conceito trata da força e do posicionamento marcante nos estudos sobre migrações internacionais das noções de nação, Estado e sociedade que passaram a constituir a forma natural, social e política do mundo moderno. Assim, o nacionalismo metodólogico perpassou a forma como os processos migratórios são percebidos e recebidos no Ocidente, lócus da criação e difusão da ideia de Estado-nação. Os autores criticam, por- 
tanto, os estudos das sociedades nacionais como entidades limitadas e naturalizadas.

Sob o enfoque do nacionalismo metodológico há, portanto, grandes chances de que estudos sobre os processos de adoecimento e a inclusão em sistemas de assistência social e saúde de grupos de imigrantes delineiem suas análises pela reificação da ideia de risco de doenças e da insegurança. A complexa situação de saúde de grupos de imigrantes e as possibilidades de sua inserção social são problematizadas por Sargent \& Larchanché 23 , que criticam a associação entre doenças infecciosas e imigrantes como grupos de risco dentro das sociedades receptoras. Outro aspecto na crítica das autoras é a constatação de que a bibliografia antropológica sobre imigração e saúde é extensa e prioriza os imigrantes sulnorte, especialmente para os Estados Unidos e Europa Ocidental, fato que pressupõe a formação de um quadro descritivo-analítico que imputa ao processo migratório e aos grupos de imigrantes, por conseguinte, o centro das análises sobre os processos de adoecimento. Logo, a compreensão da complexa trama mundial que inclui a mobilidade sul-sul permanece obscurecida.

Nesse contexto, vários são os questionamentos metodológicos com os quais se tem deparado. Em relação à posição ocupada pelo pesquisador no campo de pesquisa, observa-se certa oscilação: ora nos posicionamos mais próximos aos imigrantes, por exemplo, quando se está dentro dos serviços e o contato ocorre pela mediação dos trabalhadores da saúde, particularmente os ACS, no contexto das ações em saúde; ora quando se ocupa uma posição mais distante, exemplificada pelas dificuldades encontradas no acesso às residências de imigrantes, seus locais de trabalho ou mesmo associações que reúnem grupos de imigrantes em suas várias finalidades.

Ocorre que, queira-se ou não, em ambas as situações, a mediação oferecida pelos trabalhadores da saúde acaba por suceder-se direta ou indiretamente nas ações no campo de pesquisa. Esse é o universo em que os trabalhadores da saúde se veem mergulhados e envolvidos, com o qual interagem intensamente, conduzidos a implicações metodológicas que vão muito além da escolha de técnicas na coleta de dados.

Os conhecimentos adquiridos na relação serviços-imigrantes pressupõem, portanto, o mapeamento da complexidade relacional aí existente 24 . Ou seja, implica, por um lado, a compreensão de elementos que expressam relações complexas entre sujeitos institucionalizados, em espaços organizacionais configurados por modelos de pensamento e práticas embasados em conhecimentos técnico-científicos, códigos de conduta para orientação profissional etc; por ou- tro lado, implica compreender distintos modos de vida dos imigrantes e suas inserções sociais comprometidas pela situação migratória, entre outros aspectos. A construção dessa atitude de compreensão se inicia pelo esforço de aproximação dos sujeitos que compõem esse universo. Uma aproximação que reconheça a existência de um complexo campo de relações sociais mediado pelos serviços de saúde.

Assim concebida a situação de pesquisa, verifica-se que é justamente dentro da complexidade das condições em que se encontra o investigador que as inflexões teóricas e metodológicas emergem e impõem conjunturas problemáticas e, simultaneamente, instigantes em seus desdobramentos. Nesse sentido, a necessidade de rever o aporte teórico-metodológico e, consequentemente, rever os próprios valores implicados nesse campo de relações, constitui tarefa essencial nos processos de investigação 25,26.

Acredita-se que o estranhamento da condição de pesquisador nesse contexto estaria de certa forma assentado na sua condição de uma espécie de "estrangeiro" imerso nesse universo. Assim representado o campo de relações em tais processos de pesquisa, verifica-se certa analogia entre a situação do pesquisador e a dos imigrantes, sendo possível encontrar certas similitudes nas duas posições ocupadas nas situações de pesquisa: a do imigrante e a do pesquisador no contexto das ações dos serviços de saúde.

O conjunto de ações organizadas pelos serviços de saúde, cuja orientação técnico-científica tem como base um conjunto de normas e protocolos pré-estabelecidos, pode muitas vezes configurar um campo de conflitos para investigadores sociais e imigrantes que desconhecem suas conexões de sentido. O acesso ao serviço é mediado por uma ordenação instituída anteriormente e, muitas vezes, distante das relações entre pesquisadores e imigrantes, o que torna o espaço de encontro entre "pesquisador-estrangeiro" e imigrantes um espaço estranho a ambos. Um estranhamento construído dentro de um espaço de relações mais reduzidas às ações e ordenações que constituem as estruturas e as formas próprias desse sistema 27.

\section{Discussão em torno da reflexividade no trabalho de campo}

Uma primeira reflexão crítica, e autocrítica, de parte daqueles que estudam o complexo e problemático campo da saúde-doença-cuidado, reside no fato de que não se pode depender exclusivamente dos serviços sanitários públicos como campos de indagação etnográfica, circunscre- 
vendo as observações unicamente nesse âmbito. Ao contrário, partindo da consideração dos múltiplos obstáculos que existem no momento de abordar populações cujos modos de vida, trabalho e moradia se encontram, em muitos casos, marcados por contextos de vulnerabilidade social que supõem situações de riscos concretos à saúde individual e dos agrupamentos familiares, deve-se promover uma imersão reflexiva nos distintos âmbitos da vida cotidiana: o laboral, o doméstico, o associativo, o lazer, entre outros 13.

Ainda que sejam muitas as dificuldades encontradas pelos pesquisadores para ter acesso aos imigrantes em tais âmbitos, acredita-se que com essa perspectiva é possível, por um lado, promover um nível maior de empatia entre o investigador e os sujeitos de estudo, gerando conhecimentos acerca do contexto da sociedade de destino, nesse caso a cidade de São Paulo, no Brasil.

A distância dos pesquisadores tem constituído um importante aspecto nessas reflexões. A ausência de documentação, a constituição de espaços domésticos e de trabalho ilegais e insalubres, além do receio em relação a viver numa sociedade que não é a sua, são alguns exemplos da dificuldade dos pesquisadores nas situações concretas de vida dos imigrantes. Muitas das incursões do presente estudo ao campo de pesquisa, no caso as visitas às oficinas de confecção e residências de imigrantes, estão coladas às ações em atenção primária à saúde desenvolvida dentro da rotina de visitas realizadas pelos ACSs, inseridos na Estratégia Saúde da Família (ESF) 9.

Os bolivianos percorrem os caminhos abertos para fora das fronteiras de seu país por razões predominantemente econômicas. Suas vidas são comprometidas pela ausência ou instabilidade no trabalho, pela falta de perspectiva de bem-estar para si e seus familiares, entre outras razões $17,28,29$. As observações realizadas junto a esses imigrantes têm levado à condução de abordagens de seus problemas de saúde que relacionem seus modos de vida, de trabalho, de moradia, suas narrativas sobre saúde e doença, além dos itinerários terapêuticos percorridos para o enfrentamento das doenças e sofrimentos. Tais abordagens ganham uma dupla interpretação: ora forjada pelas considerações dos trabalhadores da saúde, ora construída por meio do contato direto com os imigrantes como sujeitos de pesquisa.

Ao se travar contato com o conjunto de serviços existentes na área central da cidade de São Paulo, observa-se a incorporação de ACS oriundos de grupos de imigrantes bolivianos, como integrantes de algumas equipes da ESF. O foco no grande contingente de imigrantes bolivianos se justifica pelo número de pessoas cadastradas em algumas unidades básicas de saúde (UBS) da região central da cidade de São Paulo. Informações do segundo semestre do ano de 2011 identificam o registro de cerca de 6.500 bolivianos somente em duas UBS: o Centro de Saúde Escola Barra Funda "Dr. Alexandre Vranjac" e na UBS do Bom Retiro 30.

Informações mais recentes demonstram um aumento considerável na produção de serviços junto aos imigrantes na cidade de São Paulo. As consultas médicas realizadas na Atenção Básica, segundo nacionalidade, no período de 2012 e 2014 , indicam que os bolivianos passaram a ocupar o segundo lugar entre os grupos atendidos, depois dos brasileiros. Os paraguaios seguem em terceiro lugar. O Sistema de Cadastramento de Usuários do SUS (CADSUS) registrou, no mês de fevereiro de 2015, um total de 39.474 estrangeiros cadastrados; entre os sul-americanos, 12.368 eram bolivianos; 1.689 paraguaios e 918 peruanos. Esses imigrantes estão concentrados principalmente na região central e se estendem às zonas leste e norte da cidade 31 . A migração internacional de bolivianos para o Brasil, anteriormente mais concentrada nas zonas fronteiriças do país, segue hoje majoritariamente com destino a São Paulo ${ }^{32}$.

Ao ser conduzido pelos ACS dentro desse conjunto de ações em atenção primária, verificase a existência de práticas inovadoras nos cuidados em saúde dos imigrantes, constituindo-se em ações inclusivas por intermédio da organização de um serviço ativo, com visitas às oficinas-domicílios e adaptando-as às necessidades observadas. Essa experiência tem demonstrado a possibilidade do desenvolvimento de práticas mais efetivas e construídas por processos de trabalho que visam dar visibilidade a segmentos populacionais específicos, estendendo os cuidados em saúde aos imigrantes bolivianos 1,33. Por exemplo, a busca pela transposição de barreiras linguísticas e culturais pelos agentes comunitários bolivianos que atuam como "tradutores"; a atuação de profissionais (enfermeiros, médicos etc.) das equipes de saúde e alunos em estágios supervisionados nas unidades de saúde com a criação de material informativo sobre campanhas sanitárias (calendário de vacinas, informativos sobre epidemias etc.) traduzidas para o idioma espanhol, ou mesmo a comunicação visual bilingue presente nos corredores e nas salas de atendimento de algumas UBS e outros serviços de saúde $3,32,33$.

Porém, constata-se que a complexidade da situação dos imigrantes impõe a necessidade de uma vigilância epistemológica permanente: percebe-se com precisão o que se pergunta e a 
quem se pergunta nos processos de pesquisa? Identifica-se um problema de natureza epistemológico-metodológico, dado que os trabalhadores-interlocutores nos processos de pesquisa atuariam como mediadores ou filtros que deixam passar somente alguns elementos da perspectiva dos imigrantes. Todo dado é um fato socialmente construído, e caberia interrogar se a fonte "primária" de dados passaria a ser, nesse caso, a "interpretação" de representantes da saúde pública sobre o ponto de vista êmico dos próprios sujeitos. Anteriormente à própria interpretação do investigador, haveria de se incluir o conjunto de pré-juízos, supostos e categorias com as quais os profissionais das equipes de saúde pública interpretam não só o problema de estudo e os próprios sujeitos de estudo, como também suas pré-concepções sobre o contexto de sua atuação 34,35.

A proposição de tal problemática incide sobre outro aspecto relevante: incorrer-se-ia em um reducionismo de pensamento se se ponderasse que os imigrantes, para resolver seus problemas de saúde ou outros tipos de aflição sofridos no contexto da sociedade para a qual migraram, procuram somente o modelo da medicina científica para obter cuidados. Segundo Sargent \& Larchanché 23 (p. 346), “as pessoas movem-se não somente entre fronteiras geográficas, mas também entre e dentro de sistemas médicos". Alguns estudos sobre o tema apontam para o fato de que há escolhas e a busca exclusiva pelos serviços públicos de saúde pode vir acompanhada de alternativas complementares pautadas em distintos modelos de atenção, dentro do marco do pluralismo assistencial existente e de acordo com a eficácia outorgada pelos sujeitos em cada caso 36. Foram coletados alguns relatos de imigrantes que procuram orientação e auxílio em igrejas cristãs, católicas ou evangélicas.

Como mostra Peirano 37 (p. 3), “a etnografia não é apenas um método, mas uma forma de ver e ouvir, uma maneira de interpretar, uma perspectiva analítica, a própria teoria em ação". Dessa maneira, essa teoria é construída não somente com a mediação dos profissionais de saúde, mas também com sua participação, incorporando as tensões existentes e vivenciadas nas relações estabelecidas no campo de pesquisa. Portanto, eles não são alheios ao processo de produção de conhecimento, mas atores no projeto relacional que os envolve também como agentes.

Colocando este fazer etnográfico no contexto dos serviços de saúde, os profissionais de saúde, imigrantes e pesquisadores são agentes que se entrelaçam nos acontecimentos cotidianos, ricos em detalhes e diversidades. Nesse cenário, os profissionais de saúde têm papel fundamen- tal no despertar deste conhecimento. Por meio de suas mediações, eles abrem caminhos para o “que não se apresenta” inicialmente.

Na etnografia realizada com a população boliviana, no Centro de Saúde Escola Barra Funda "Dr. Alexandre Vranjac" (UBS vinculada à Irmandade de Misericórdia da Santa Casa de São Paulo), a ponte de acesso para esses nichos foram os ACS. Eles têm os registros e os mapas de todas as famílias imigrantes residentes na região e mantêm uma relação muito próxima de confiança, o que possibilitou a imersão dos pesquisadores no seu cotidiano. A pesquisa de campo foi realizada no período de outubro a dezembro de 2015 e janeiro e fevereiro de 2016. Foram visitadas 13 oficinas de confecção de roupas e domicílios de imigrantes bolivianos cadastrados e acompanhados para atendimento pelo serviço de atenção primária em saúde.

Dessa aproximação com os bolivianos, outras pontes foram construídas para compreender as dinâmicas e arranjos sociais estabelecidos. Saiu-se do contexto do serviço e buscaram-se parcerias com Organizações Não-Governamentais (ONGs), lideranças comunitárias, formadores de opinião e pessoas que fomentam as manifestações culturais dos bolivianos em São Paulo. Essa estratégia permitiu uma aproximação da diversidade e complexidade da população do estudo.

Esse movimento permitiu que a leitura da investigação fosse ampliada e se pudesse analisar o olhar do profissional de saúde com seus saberes técnicos - e de certa forma familiares -, aproximando-se do contexto sociocultural dos imigrantes.

O centro de saúde foi um dos locais da pesquisa de campo, centralizador das atividades. Pôde-se visitar 13 oficinas de costura onde os imigrantes trabalhavam e, em muitos casos, também estavam domiciliados. Circulou-se pelas ruas e praças, participou-se das festas locais na feira dominical na Praça da Kantuta (espaço de encontro estabelecido pelos imigrantes no bairro do Pari, área central da cidade) e foram conhecidas algumas ONGs, também. Teve-se acesso às associações de imigrantes, aos grupos de futebol de mulheres bolivianas, grupos de músicas típicas e danças folclóricas, aos locais para envio de dinheiro para a Bolívia e recrutamento de trabalhadores, à associação dos residentes bolivianos, a consultas com um Xamã andino, entre outros. Desse modo, ao se inserir nos espaços de convivência dos imigrantes como pesquisador, estabeleceu-se uma relação dialógica com eles do que é novo para os imigrantes, do que é novo para os pesquisadores e de como isso se relaciona com as concepções sobre cuidado, saúde e o entendimento das doenças e dos sofrimentos. 
Como exemplo, uma das incursões se deu junto à Associação dos Residentes Bolivianos. Essa associação realiza, em seu Centro Médico, assistência médica e odontológica gratuita ou a preços populares aos imigrantes bolivianos, com um atendimento realizado inteiramente por profissionais de saúde vindos da Bolívia. O atendimento ambulatorial ocorre dentro da sede do Centro Integrado do Migrante, onde também é possível realizar consultas contábeis e jurídicas relacionadas à imigração, despacho de documentos, preparação de processos, vistos permanentes, registro de filhos e envio de dinheiro para outros países. Santos 36 mostra, no caso dos imigrantes haitianos no Amazonas, que são movimentos que envolvem a manutenção de laços de parentesco, econômicos, religiosos e afetivos entre os que migram e os que ficam nos países de origem.

Essa parceria surgiu com as pesquisas on-line sobre conteúdos que fizessem referência à comunidade boliviana na cidade de São Paulo e se concretizou em uma das incursões por um dos espaços de compartilhamento da comunidade boliviana, na Rua Coimbra, onde semanalmente ocorre uma feira com elementos típicos da cultura boliviana que se localiza nas proximidades do Centro Médico.

Realizou-se contato com os responsáveis pela Associação e passou-se a frequentar seus espaços para a interação com o campo. Foi dado início ao projeto para realização de campanhas para promoção da saúde em parceria com os profissionais que atuam no Centro Médico. O foco de abordagem nessa parceria voluntária eram as questões relacionadas à prevenção da tuberculose entre os imigrantes bolivianos. Vale ressaltar que o grupo de pesquisadores é composto por antropólogos, sociólogo, psicóloga e enfermeira. Contou-se também com a colaboração de informantes-chave bolivianas, com formação em enfermagem, além de agentes comunitárias de saúde, sendo uma boliviana e uma enfermeira chilena.

A circulação dos pesquisadores nos espaços ocupados pelos imigrantes também evidencia a diferença em seu comportamento nos contatos realizados na presença dos agentes de saúde, onde eles se mantêm de modo mais formal, em um tom biomédico, quase como se estivessem em entrevista com a "federal" (alusão à polícia federal, responsável pelo processo de legalização documental de imigrantes). Embora estejam familiarizados com as pessoas e as especificidades locais, ainda se sentem incomodados. Durante as visitas às oficinas de costura, também houve dificuldades em estabelecer conversas mais "à vontade”. Havia o constrangimento do tempo, pois a remuneração é proporcional ao número de peças confeccionadas, pela ausência de privacidade (o local de trabalho e moradia é coletivo) e talvez pela presença dos agentes comunitários de saúde que representam uma instituição.

Por outro lado, quando estão em eventos da comunidade boliviana, o clima é descontraído, sentiam-se à vontade e olhavam os pesquisadores como estrangeiros, do seu lugar de nativos naquele ambiente. A abertura para a participação em grupos de Whatsapp das associações bolivianas, em que são compartilhadas as alegrias com as festas comemorativas, a expectativa com a realização das provas do Revalida (prova oficial para revalidar diplomas de medicina emitidos fora do Brasil) pelos médicos bolivianos e até mesmo na observação da elaboração de estratégias para lidar com essas angústias, como a organização de grupos de estudo dos médicos, são exemplos da dinâmica das relações entre os imigrantes, muitas vezes desconhecidas dos pesquisadores e, também, dos profissionais de saúde.

É interessante notar, inclusive, tal comportamento diferenciado nas campanhas de saúde que ocorrem na Associação dos Residentes Bolivianos, onde, apesar de o ambiente ser ambulatorial, as pessoas se sentem à vontade para questionar, tirar dúvidas e até se expressar corporalmente de um modo que não fariam se não se reconhecessem entre pares. As mulheres se demonstravam desinibidas para falarem mais, para se colocarem durante os diálogos e em alguns casos se tornavam mais falantes que os esposos, em contrapartida ao observado nas visitas com os agentes de saúde.

Por outro lado, verificou-se a pouca expressão verbal produzida nas situações de entrevistas com os imigrantes. Esse comportamento é mais acentuado nas mulheres, sendo muito frequentes relatos dos profissionais de saúde que imputam ao domínio masculino, no âmbito doméstico e nas situações de trabalho, o controle sobre as mulheres. Atitudes de submissão, pautadas particularmente no silêncio das mulheres perante a fala dos homens, são muito comuns. Cabe refletir sobre o fato de que as narrativas dessas situações sobre as mulheres são feitas quase sempre, por trabalhadoras do sistema de saúde, especialmente do corpo de funcionárias de enfermagem (profissional e ocupacional) das equipes de saúde.

A complexidade das experiências vividas pelos imigrantes se desvela no espaço relacional constituído pelos serviços de saúde. Suas condições de saúde, quase sempre comprometidas pelas precárias condições de vida, expressam um quadro situacional complexo e difícil de ser alcançado pelos instrumentos e ações das políticas 
em saúde. Tal constatação expõe necessariamente os dilemas em relação a um conjunto ampliado de situações de risco a que estão sujeitas as pessoas em situação de migração 38,39,40.

A crescente evolução de casos de tuberculose entre imigrantes bolivianos na cidade de São Paulo emerge principalmente no contexto de formação de fluxos migratórios internacionais intimamente associados à produção têxtil, e dos desdobramentos sociossanitários decorrentes dessa dinâmica. Boa parte dos imigrantes, em particular os sul-americanos, sofre as iniquidades decorridas dos processos migratórios internacionais, intensificados por experiências penosas de trabalho e condições precárias de moradia. A emergência de um conjunto de doenças infectocontagiosas, como a tuberculose e a doença de Chagas, tem provocado dificuldades nos planos da vigilância à saúde, no controle do surgimento de novos casos e na adesão ao tratamento também 6,7,9,11,41.

Constatou-se a relevância de colocar em perspectiva todas as vivências e observações, posicionando o pesquisador em seu lugar de instrumento de pesquisa e produtor de conhecimento por meio do exercício de interpretação do campo, compreensão do empírico e participação ativa nos processos, e que no caso desta pesquisa, apresenta também os problemas da interculturalidade discutida por Menéndez 42.

\section{Considerações finais}

Não é raro que nas experiências de pesquisa e nos relatos coletados junto aos trabalhadores venham à tona casos de situações de pessoas e grupos de imigrantes em que seus direitos estejam solapados pela situação migratória, o que é extensamente citado pela literatura nacional e internacional, conforme citado anteriormente.

As redes de atenção à saúde, particularmente a atenção primária, têm sido um campo privilegiado de investigação. As interconexões de serviços formam um emaranhado de ações decorrentes das relações entre as demandas dos imigrantes, os trabalhadores e gestores em saúde e a participação dos pesquisadores como observadores e participantes de muitas das atividades desenvolvidas dentro e fora dos serviços de saúde. A produção de conhecimentos sobre as condições de vida e de saúde dos imigrantes, seus modos particulares de viver as experiências, suas concepções sobre os processos de adoecimento e itinerários terapêuticos, constituem importante tarefa a ser desenvolvida no contexto das múltiplas ações em saúde.

O lugar do trabalhador em saúde nessas pesquisas, seja por lidar cotidianamente com os imigrantes, seja pela introdução do pesquisador em seu cotidiano mediante visitas domiciliares, não os remete a meros "tradutores" ou informantes dos usuários. Eles não emprestam somente seu "olhar", como citado na epígrafe, tampouco são mediadores do contato com os imigrantes. Eles são partícipes dessas pesquisas com uma perspectiva técnica que não se limita a ela. Também são afetados e protagonistas das relações construídas no processo da pesquisa.

\section{Agradecimentos}

Agradecemos aos professores Doutores Ione Guibu e Manoel Carlos Ribeiro por acreditar no projeto Estudo Etno-Epidemiológico sobre a Tuberculose entre os Imigrantes Bolivianos na Cidade de São Paulo e possibilitar sua realização por meio do Centro de Estudos Augusto Leopoldo Ayrosa Galvão (CEALAG). Agradecemos à equipe Estratégia Saúde da Família do Centro de Saúde Escola Barra Funda “Dr. Alexandre Vranjac”, Irmandade da Santa Casa de Misericórdia de São Paulo. 


\section{Referências}

1. Marsiglia RMG, Silveira C, Carneiro JN. Políticas sociais: desigualdade, universalidade e focalização na saúde no Brasil. Saúde Soc 2005; 14:69-76.

2. Carneiro Junior N, Andrade MC, Luppi CG, Silveira C. Organização de práticas de saúde equânimes em atenção primária em região metropolitana no contexto dos processos de inclusão e exclusão social. Saúde Soc 2006; 15:30-9.

3. Carneiro Junior N, Oliveira L, Jesus CH, Luppi CG. Migração, exclusão social e serviços de saúde: o caso da população boliviana no centro da cidade de São Paulo. BIS Bol Inst Saúde 2011; 13:177-81.

4. Tambellini E, Mascaro L, Silva UVA. Inclusão de imigrantes bolivianos na cidade de São Paulo: algumas estratégias e políticas locais. In: Silveira C, Carneiro Junior N, Marsiglia RMG, organizadores. Projeto Inclusão Social Urbana: Nós do Centro. Metodologia de pesquisa e de ação para inclusão social de grupos em situação de vulnerabilidade no centro da cidade de São Paulo. São Paulo: Fundação Arnaldo Vieira de Carvalho/Faculdade de Ciências Médicas da Santa Casa de São Paulo; 2009. p. 123-68.

5. Goldberg A. Salud e interculturalidad: aportes de la antropología médica para un abordaje sociosanitario de la población boliviana de la Ciudad Autónoma de Buenos Aires. In: Gobierno de la Ciudad de Buenos Aires, editor. Buenos Aires boliviana. v. 1. Buenos Aires: Comisión para la Preservación del Patrimonio Histórico Cultural de la Ciudad de Buenos Aires; 2009. p. 233-46.

6. Goldberg A. Análisis de la relevancia de los factores socioculturales en el proceso asistencial de pacientes con tuberculosis, usuarios del Instituto Vaccarezza-Hospital Muñiz. Un abordaje etnográfico desde la Antropología Médica. Rev Argent Salud Pública 2010; 1:13-21.

7. Goldberg A. A comparative anthropological approach around the incidence of Chagas and tuberculosis diseases in Bolivian migrants in Barcelona and Buenos Aires, respectively. Eä Journal 2010; 1(3). http://issuu.com/eajournal/docs/inciden cia-chagas-tuberculosis-inmigrantes.

8. Goldberg A. Tuberculosis en inmigrantes bolivianos del Área Metropolitana de Buenos Aires: narrativas y procesos asistenciales. In: Martínez Hernáez A, Masana L, Di Giacomo S, editores. Evidencias y narrativas en la atención sanitaria: una perspectiva antropológica. Tarragona: Publicaciones Universidad Rovira y Virgili/Porto Alegre: Rede Unida; 2013. p. 113-36.

9. Goldberg A, Silveira C. Social inequality, access conditions to public health care and processes of care in Bolivian immigrants in Buenos Aires and São Paulo: a comparative inquiry. Saúde Soc 2013; 22:283-97.

10. Silveira C, Carneiro Junior N, Ribeiro MCSA, Barata RCB. Living conditions and access to health services by Bolivian immigrants in the city of São Paulo, Brazil. Cad Saúde Pública 2013; 29:2017-27.
11. Goldberg A. Contextos de vulnerabilidad social y situaciones de riesgo para la salud: tuberculosis en inmigrantes bolivianos que trabajan y viven en talleres textiles clandestinos de Buenos Aires. Cuadernos de Antropología Social 2014; 39:91-114.

12. Mota A, Marinho MGSMC, Silveira C. Saúde e história de migrantes e imigrantes: direitos, instituições e circularidades. v. 5. São Paulo: Faculdade de Medicina, Universidade de São Paulo/Universidade Federal do ABC/Casa de Soluções e Editora; 2014.

13. Goldberg A, Martin D, Silveira C. Por um campo específico de estudos sobre processos migratórios e de saúde na saúde coletiva. Interface Comun Saúde Educ 2015; 19:229-32.

14. Silva SA. A migração dos símbolos: diálogo intercultural e processos identitários entre os bolivianos em São Paulo. São Paulo Perspect 2005; 19:77-83.

15. Silva SA. Bolivianos em São Paulo: entre o sonho e a realidade. Estud Av 2006; 20:157-70.

16. Baeninger R. Imigração boliviana no Brasil. Campinas: Núcleo de Estudos de População, Universidade Estadual de Campinas; 2012.

17. Rizek CS, Georges I, Silva CF. Work and immigration: a comparative study of Brazil and Argentina. Lua Nova 2010; 79:111-42.

18. Souchaud SA. Imigração boliviana em São Paulo. In: Ferreira AP, Vainer C, Póvoa Neto H, Santos MO, organizadores. A experiência migrante: entre deslocamentos e reconstruções. Rio de Janeiro: Editora Garamond; 2010. p. 72-95.

19. Silveira C, Carneiro Junior N, Marsiglia RMG, organizadores. Projeto Inclusão Social Urbana: Nós do Centro. Metodologia de pesquisa e de ação para inclusão social de grupos em situação de vulnerabilidade no centro da cidade de São Paulo. São Paulo: Fundação Arnaldo Vieira de Carvalho/Faculdade de Ciências Médicas da Santa Casa de São Paulo; 2009.

20. WaldmanTC. Movimentos migratórios sob a perspectiva do direito à saúde: imigrantes bolivianas em São Paulo. Rev Direito Sanit 2011; 12:90-114.

21. Martes ACB, Faleiros SM. Acesso dos imigrantes bolivianos aos serviços públicos de saúde na cidade de São Paulo. Saúde Soc 2013; 22:351-64.

22. Wimmer A, Schiller NG. Methodological nationalism and beyond: nation-state building, migration and the social sciences. Glob Netw 2002; 2:301-34.

23. Sargent C, Larchanché S. Transnational migration and global health: the production and management of risk, illness and access to care. Ann Rev Anthropol 2011; 40:345-61.

24. Bruyne P, Herman J, Schoutheete M. Dinâmica da pesquisa em ciências sociais. 2a Ed. Rio de Janeiro: Francisco Alves; 1982.

25. Gomes MHA, Silveira C. Sobre o uso de métodos qualitativos em saúde coletiva, ou a falta que faz uma teoria. Rev Saúde Pública 2012; 46:160-5. 
26. Gomes MHA, Martin D, Silveira C. Comentários pertinentes sobre usos de metodologias qualitativas em saúde coletiva. Interface Comun Saúde Educ 2014; 18:469-77.

27. Cardoso R. A aventura antropológica. Rio de Janeiro: Editora Paz e Terra; 1986.

28. Silva SA. Hispânico ou latino: faces de um processo identitário entre imigrantes sul-americanos em São Paulo. In: Paiva OC, organizador. Migrações internacionais: desafios para o século XXI. São Paulo: Memorial da América Latina; 2007. p. 5-212.

29. Bolívia Cultural Notícias. UBS Bom Retiro e comunidade boliviana trabalhando pela saúde. http://www.boliviacultural.com.br/ver_noticias. php?id=586 (acessado em 03/Mar/2016).

30. Araujo APC, Filartigas DME, Carvalho LC. Bolivianos no Brasil: migração internacional pelo corredor fronteiriço Puerto Quijarro (BO)/Corumbá (MS). Interações Estud Pesqui Psicol 2015; 16:131-41.

31. Coordenação de Epidemiologia e Informação, Secretaria Municipal da Saúde de São Paulo. Boletim CEInfo - Saúde em Dados 2015; Ano XIV, no 14.

32. Calixto FM, Loureiro JS, Garcia CE, Simões O. PróSaúde: uma resposta para a necessidade de informações de mães imigrantes na região central da cidade de São Paulo. Rev Bras Educ Méd 2012; 36:223-7.

33. Carneiro JN, Silveira C. Organização das práticas de atenção primária no contexto dos processos de exclusão/inclusão social. Cad Saúde Pública 2003; 19:1827-35.

34. Menéndez E. La parte negada de la cultura. Relativismo, diferencia y racismo. Barcelona: Ediciones Bellaterra; 2002.

35. Ramirez HS. Calidad de atención en salud. Prácticas y representaciones sociales en las poblaciones quechua y aymará del altiplano boliviano. La Paz: Organización Panamericana de la Salud/Organización Mundial de la Salud; 2009.
36. Santos FVA. Inclusão dos migrantes internacionais nas políticas do sistema de saúde brasileiro: o caso dos haitianos no Amazonas. Hist Ciênc Saúde -Manguinhos 2016; 23:477-94.

37. Peirano M. Etnografia, ou a teoria vivida. Ponto Urbe 2008; 2:2-9.

38. Barradas RB, Ribeiro MCSA, Cassanti AC; Grupo do Projeto Vulnerabilidade Social no Centro de São Paulo. Social vulnerability and health status: a household survey in the central area of a Brazilian metropolis. Cad Saúde Pública 2011; 27 Suppl 2:S164-75.

39. Silveira C, Ribeiro MCSA, Carneiro Junior N, Simões O, Barata RB. Processos migratórios e Saúde: uma breve discussão sobre abordagens teóricas nas análises em saúde dos imigrantes no espaço urbano. In: Mota A, Marinho MGSMC, Silveira C, organizadores. Saúde e história de migrantes e imigrantes: direitos, instituições e circularidades. v. 5. São Paulo: Faculdade de Medicina, Universidade de São Paulo/Universidade Federal do ABC/ Casa de Soluções e Editora; 2014. p. 93-108.

40. Zimmerman C, Kiss L, Hossain M. Migration and health: a framework for 21st Century Policy-Making. PLoS Med 2011; 8:e1001034.

41. MartinezVN. Equidade em saúde: o caso da tuberculose na comunidade de bolivianos na cidade de São Paulo [Dissertação de Mestrado]. São Paulo: Faculdade de Saúde Pública, Universidade de São Paulo; 2010.

42. Menéndez E. Salud intercultural: propuestas, acciónes y fracasos. Ciênc Saúde Coletiva 2016; 21:109-18. 


\section{Abstract}

Studies on the health-disease-healthcare process in immigrants settled in the city of São Paulo, Brazil, have revealed a complex web of relations in the demands by immigrants and the actions conceived and planned by health services. In this context, intermediation by health workers in the relationship between immigrants and researchers has constituted an important form of access by the latter to South American immigrants, especially Bolivians. During research, access to immigrants occurs within the context of health actions, facilitating the researchers' access to immigrants' homes, workplaces, and even associations. Understanding the processes of illness in immigrants within the complex web of relations among institutional health workers in organizational spaces shaped by models of thinking based on biomedicine led us to problematize the possibilities for an approach to subjects that comprise this universe.

Immigrants; Health Personnel; Qualitative Research

\section{Resumen}

Los estudios sobre el proceso salud-enfermedad-cuidados de inmigrantes, establecidos en la ciudad de Sao Paulo, Brasil, han evidenciado una compleja trama de relaciones en las demandas de los inmigrantes y en las acciones concebidas y planeadas por los servicios de salud. En ese contexto, la intermediación de los trabajadores de la salud en la relación inmigrantes-investigadores constituye una importante forma de acceso de los últimos a los inmigrantes sudamericanos, especialmente los bolivianos. Durante las investigaciones, el acceso a los inmigrantes se produce dentro de los contextos de las acciones en salud, facilitando a los investigadores el acceso a las residencias de los inmigrantes, sus lugares de trabajo o incluso asociaciones. La comprensión de los procesos de enfermedad de los inmigrantes, dentro de la compleja trama de relaciones entre trabajadores institucionalizados en espacios organizativos configurados por modelos de pensamiento, fundados en la biomedicina, nos conduce a problematizar las posibilidades de aproximación junto a los sujetos que componen tal universo.

Inmigrantes; Personal de Salud; Investigación Cualitativa
Recebido em 18/Abr/2016

Versão final reapresentada em 15/Jul/2016 Aprovado em 08/Set/2016 